\title{
Can resistant coral-Symbiodinium associations enable coral communities to survive climate change? A study of a site exposed to long-term hot water input
}

Climate change has led to a decline in the health of corals and coral reefs around the world. Studies have shown that, while some corals can cope with natural and anthropogenic stressors either through resistance mechanisms of coral hosts or through sustainable relationships with Symbiodinium clades or types, many coral species cannot. Here, we show that the corals present in a reef in southern Taiwan, and exposed to long-term elevated seawater temperatures due to the presence of a nuclear power plant outlet (NPP OL), are unique in terms of species and associated Symbiodinium types. At shallow depths $(<3 \mathrm{~m})$, eleven coral genera elsewhere in Kenting predominantly found with Symbiodinium types C1 and C3 (stress sensitive) were instead hosting Symbiodinium type D1a (stress tolerant) or a mixture of Symbiodinium type C1/C3/C21a/C15 and Symbiodinium type D1a. Of the 16 coral genera that dominate the local reefs, two that are apparently unable to associate with Symbiodinium type D1a are not present at NPP OL at depths of $<3 \mathrm{~m}$. Two other genera present at NPP OL and other locations host a specific type of Symbiodinium type C15. These data imply that coral assemblages may have the capacity to maintain their presence at the generic level against long-term disturbances such as elevated seawater temperatures by acclimatization through successful association with a stress-tolerant Symbiodinium over time. However, at the community level it comes at the cost of some coral genera being lost, suggesting that species unable to associate with a stress-tolerant Symbiodinium are likely to become extinct locally and unfavorable shifts in coral communities are likely to occur under the impact of climate change. 
1 Keshavmurthy Shashank ${ }^{1}$, Pei-Jei Meng, ${ }^{2,3}$, Jih-Terng Wang ${ }^{4}$, Chao-Yang Kuo ${ }^{1,5}$, Sung-Yin

2 Yang $^{6}$, Chia-Min Hsu ${ }^{1,7}$, Chai-Hsia Gan ${ }^{1}$, Chang-Feng Dai ${ }^{7}$, Chaolun Allen Chen ${ }^{1,78^{*}}$

\section{Affiliations:}

$4 \quad{ }^{1}$ Biodiversity Research Centre, Academia Sinica, Nangang, Taipei, 115, Taiwan

$5 \quad{ }^{2}$ National Museum of Marine Biology/Aquarium, Checheng, Pintung, 944, Taiwan

$6{ }^{3}$ Institute of Marine Biodiversity and Evolution, National Dong Hwa University, Checheng,

7 Pingtung 944, Taiwan

$8{ }^{4}$ Institute of Biotechnology, Tajen University of Science and Technology, Pintung, 907, Taiwan

$9{ }^{5}$ ARC Centre for Coral Reef Studies, James Cook University, Townsville, 4811, Australia

$10{ }^{6}$ University of Ryukyus, Graduate school of Engineering and Science, Okinawa 903-0213, Japan

$11{ }^{7}$ Institute of Oceanography, National Taiwan University, Taipei, 106, Taiwan

$12{ }^{8}$ Taiwan International Graduate Program (TIGP)-Biodiversity, Academia Sinica, Nangnag, Taipei 13 115, Taiwan

17 Corresponding author: Dr. Allen Chen, Research Fellow, Biodiversity Research Center, 18 Academia Sinica, Nangang, Taipei 115, Taiwan.

19 Tel: 8862 27899549; Fax: 886-2-27858059; E-mail: cac@gate.sinica.edu.tw 
24

25

26

27

28

29

30

31

32

33

34

35

36

37

38

39

40

41

42

43

44

45

46

As a result of global change, tropical ocean temperatures are predicted to rise between 1.0

to $3.0{ }^{\circ} \mathrm{C}$ by the end of this century (IPCC 2013) in addition to fluctuation resulting from an increase in minimum and maximum temperatures with daily minimum temperatures rising more rapidly than maximums (Traill et al. 2010; Vose et al. 2005). Evidence from research has shown a higher sensitivity to global warming in tropical species since they are exposed to narrower thermal niches (Kozak and Wiens 2007). Coral holobionts (in this paper refers to coral host + zooxanthellae, see Weber and Medina 2012) are known to be living at, or near, their tipping points (Donelson and Munday 2012; Monaco and Helmuth 2011) across a range of different thermal environments (Ladner et al. 2011). In the absence of significant mechanisms to resist stress, corals will likely face high levels of regional mortality through time (Ladner et al. 2011). For corals, it is now imperative to be able overcome the effects of climate change and continue to survive. The question remains as to whether every coral species can overcome the effects of climate change. It is necessary for the whole coral community in any given location to survive, as survival of only a few species cannot maintain the coral reef community. Marshall and Baird (2000) have suggested that the change in community structure and species diversity is a result of the differences among species in their susceptibilities to disturbance. The fact that relatively small excursions of seawater temperature can have large-scale impacts on coral survival indicates that reef-building corals are living close to their upper thermal limit (Fitt et al. 2001; Riegl et al. 2011). If environmental perturbations exceed the adaptive capacity of corals, it may result in a change in their communities over time such that species that are phenotypically plastic or can adapt genetically through time will become dominant. In a disturbed environment where organisms under constant stress or challenged by increasing stress over time (for example, 
47 salinity or temperature increases), the number of individuals exposed to selection will be greater resulting in an overall shift in abundance and a change in composition (Bell 2012).

Over short periods of time (within a single generation), the potential for corals to acclimatize to climate change through phenotypic plasticity or by specific combinations with stress resistant Symbiodinium types thorough natural selection may be the over-riding determinant of survival (Marshall and Baird 2000). However, a beneficial association between a coral host and Symbiodinium is a rather complex and holistic process because the classification of Symbiodinium into functionally distinct evolutionary entities (using alpha-numeric designations equivalent to 'species') has shown them to belong to nine divergent phylogenetic 'clades' (A to I) (Pochon and Gates 2010). Corals associate with either single or multiple Symbiodinium clades, and occupy defined ecological niches and roles within and across coral hosts (LaJeunesse et al 2010; Pochon and Gates 2010; Weber and Medina 2012) based on their physiological response, some of which includes photosynthetic efficiency (Iglesias-Peieto et al. 2004) and sensitivity or tolerance to heat stress (Baker 2003a,b; Jones et al. 2008; Little et al. 2004; Rown 2004;

61 Sampayo et al. 2008; Warner et al. 2006), light adaptation. While spatial pattern in symbiont communities can be explaned through identification at the clade level, the exclusion of intracladal differences more often obscures ecological patterns in Symbiodinium distribution (Tong et al. 2013). With increasing attention and advanced sequencing methods, diverse 'sub species' or 'types' have been discovered within the Symbiodinium clades, and various studies have discussed on length about the Symbiodinium type physiological differences and their contribution to coral host stress resistance. Similar to the case of Symbiodinium clade; geographic locations, local environmental conditions (differences in physical parameters such as temperature, light and turbidity) have been found to define the Symbiodinium type associated with coral hosts. For 
70

71

72

73

74

75

76

77

78

79

80

81

82

83

84

85

86

87

88

89

90

91

92

example, corals present in shallow and turbid locations are found to be associated with Symbiodinium type D1a (LaJeunesse et al. 2010) or the distribution of Symbiodinium types according to different light environments (Farde et al. 2008). Thornhill et al. (2006) have shown that Orbicella annularis from Florida Key were associated with Symbiodinium type D1a after the 1998 bleaching event and reverted back to being associated with Symbiodinium type B10 after 2002. Results from the laboratory experiments have shown difference in tolerance to temperature stress (Brading et al. 2011; Fisher et al. 2012; Kramer et al. 2012; Wang et al. 2012). For example, Symbiodinium type A1 was found to be more tolerant to temperature stress compared to types C1 and B1 (Hawkins and Davy 2012) and Symbiodinium type C15 was more tolerant than type C3 in terms of their photosynthetic efficiency. With respect to Symbiodinium type D1a; studies have shown highest activation energy when subjected to temperature stress in freshly isolated D1a when compared to B1, C1, C3 and C15 types (Wang et al. 2012). In a cold temperature stress experiment, Thornhill et al. 2008 showed that Symbiodinium type B2 displayed rapid and full recovery at $10^{\circ} \mathrm{C}$ for 2 -week period in their photochemical efficiency compared to types A3, B1 and C2 (Fisher et al. 2012). These studies have revealed the importance of Symbiodinium types in assisting the coral host resisting mechanisms to stress.

In addition to associating with a resistant Symbiodinium clade/type, corals can overcome environmental perturbations, mainly seawater temperature fluctuations, by their ability to shuffle between clades/types depending on the environmental and seasonal condition (LaJeunesse et al. 2004, Chen et al. 2005, Thornhill et al. 2006, Sampayo et al. 2008, LaJeunesse et al. 2010a, Chen et al. 2005, Hsu et al. 2012, Keshavmurthy et al. 2012). It has often been found that corals 1 associating with stress resistant Symbiodinium clade D have experienced community changes that 2 resulted in some coral species being favored over others (Marshall and Baird 2000; Loya et al. 
93 2001). Studies have shown the possible ability of coral and various Symbiodinium combinations

94 to respond to the effects of climate change as a result of a high degree of variation in coral and 95 symbiont thermal tolerance and symbiont community shifts in response to thermal tolerance

96 (Marshall and McCulloch, 2002; Hughes et al. 2003; Baker 2001; Baker et al. 2004; Berkelmans

97 and Van Oppen 2006). Short-term field or laboratory studies that have been performed to

98 understand the acclimatization and/or adaptation potential in corals to climate change (Meesters

99 et al. 2002; Coles and Brown 2003; Ayre and Hughes 2004; Baker et al. 2004; Rowan 2004;

100 Richier et al. 2005; Berkelmans and Van Oppen 2006; Gittenberger and Hoeksema 2006; Shaish

101 et al. 2007; Strychar and Sammarco, 2009; Hennige et al. 2010; Barshis et al. 2010; Oliver and

102 Palumbi 2011; Bellantuono et al. 2011; Keshavmurthy et al. 2012; Howells et al. 2013) have

103 their own shortfalls. To understand more comprehensively the capacity of acclimatization and

104 adaptation, a more effective way would be to conduct mesocosm experiments by mimicking

105 different perturbations of climate change, but such experiments are difficult to conduct and suffer

106 from logistical problems. Another way is to find a location that already is in a situation where

107 seawater temperatures are similar to levels predicted for 2050 by IPCC and is also subjected to

108 natural and anthropogenic disturbances over time.

109

In Kenting, southern Taiwan, there is an area that is influenced by constant hot-water

110 effluent from a nuclear power plant located along the western side of Nanwan Bay that has been

111 operating since 1984. At this nuclear power plant outlet (NPP OL), the average seawater

112 temperature is 2.0 is $2 .{ }^{\circ} \mathrm{C}$ higher than at other coral reef sites in Kenting (Fan et al. 1991; Pier

113 2011; also see Keshavmurthy et al. 2012). Hot water at the nuclear power plant (NPP) site is

114 trapped and flows southwestward in Nanwan Bay because of a near-shore current and tides

115 (Chiou et al. 1993). The hot water released in this area has had an impact on the marine ecology 
116 within the area of dispersal (Chiou et al. 1993; Hung and Huang 1998; Jan et al. 2001; Hwang et

117 al. 2004). Recent studies on two coral species, Isopora palifera and Platygyra verweyi (sampling

118 done on a local scale in Kenting, Taiwan), showed a differential trend in associating with

119 Symbiodinium type D1a. For example, P. verweyi, distributed in shallow waters at depths of

120 2ociating with $\mathrm{g}$ with he marine ecology within the area of dispersaspecies does not show

121 obvious bleaching at NPP OL even though it is constantly exposed to warm water, and is

122 associated with Symbiodinium type D1a, whereas it associates with Symbiodinium type C3 in

123 cooler waters (Keshavmurthy et al. 2012). In the case of Isopora palifera, it overcomes the effect

124 of hot water at NPP OL by shuffling its Symbiodinium clades seasonally (Hsu et al. 2012) and

125 through the presence of exclusive stress-resistant haplotypes of the host (Hsu et al. 2012).

By utilizing Kenting and NPP OL as a natural mesocosm, we were able to investigate the

127 present composition of the coral community and associated Symbidodinium types in sixteen genera of reef-building corals exposed to elevated seawater temperatures over the previous 26 years. For comparison, we sampled the same sixteen genera from seven adjacent sites that are not under the influence of the nuclear power plant's hot water effluent to see how a long-term

131 environmental perturbation (in this case seawater temperature) affected present day coral132 Symbiodinium and coral host composition. Due to the lack of historical Symbiodinium 133 composition data, and although it is not possible to show the process of acclimatization, we based 134 our study on the hypothesis that the present composition of coral-Symbiodinium and coral hosts at

135 the nuclear power plant location is the result of acclimative and/or adaptive phenotypic plasticity 136 during 26 years of exposure to chronically elevated seawater temperatures. This could be due to 137 the plasticity in the coral hosts or to associations with resistant Symbiodinium types. By 138 conducting large-scale sampling from 16 coral genera, this study attempts to understand how 
139 different coral species in a community might have adjusted or responded to long-term elevated

140 seawater temperature stress. The possible outcomes are that either all corals exposed to chronic

141 seawater temperature stress host only resistant types of Symbiodinium, or only those corals that

142 are able to host resistant Symbiodinium types can survive. We discuss whether resistance at the

143 genus or species level, if any, towards the long-term warming of seawater temperatures will

144 enable corals at the community level to survive the effects of climate change.

145 Material and Methods

146 Area description and Sampling

147 Coral samples were obtained from eight sites present in Nanwan, Kenting located at the

148 southern tip of Taiwan (Fig. 1). Of the eight sites, one was the nuclear power plant outlet (NPP

149 OL), which was considered a natural mesocosm subject to long-term hot water perturbation.

150 Seawater in the bay comes from the Kuroshio Current in winter and South China Sea current in

151 summer. The average sea surface temperature in this bay is $29.0^{\circ} \mathrm{C}$ in summer and $24.0{ }^{\circ} \mathrm{C}$ in

152 winter. A total of 1913 coral colonies belonging to 60 species from 16 genera and representing 7

153 families were sampled in 2009 and 2010 from $3 \mathrm{~m}$ and $7 \mathrm{~m}$ depths from eight sites; Wanlitung

154 (WLT), NPP OL, Houbihu (HBH), NPP Inlet (IL), Taioshih (TS), Tanziwan (TZW), Sanjiawan

155 (SJW), and Longken (LK), including the reef near the NPP outlet (Fig. 1). Corals sampling was

156 authorized by Kenting National Park project \#488-100-01. For every coral genus sampled, a

157 minimum of 15 colonies were collected from each location, if available, at each designated

158 sampling depth. At some sampled sites, it was not possible to find even one colony of some

159 genera, while at other sites the minimum sample was 1 and maximum was 35 . Hence, it was not

160 possible to maintain uniformity in sample number due to the uneven distribution of coral genera. 
161 All samples were immediately fixed in 90\% ethanol and stored until further analysis of 162 Symbiodinium clades.

163

164

165

166

167

168

169

170

171

172

173

174

175

176

177

178

179

180

181

\section{DNA extraction}

DNA was extracted using the high-salt DNA extraction method that was modified according to Ferrara et al. (2006). Approximately $30 \mathrm{mg}$ of coral were placed in $2 \mathrm{ml}$ Eppendorf tubes into which $200 \mu \mathrm{t}$ lysis buffer (1 M Tris-Boric, 0.5 M EDTA (pH 8), 20\% sodium dodecylsulfate, and $5 \mathrm{M} \mathrm{NaCl})$ and $\underline{10}$ an of proteinase $\mathrm{K}\left(10 \mathrm{mg} \mathrm{ml}^{-1}\right)$ were added and incubated overnight in a $60{ }^{\circ} \mathrm{C}$ water bath. After incubation, an equal volume (210 te) of $\mathrm{NaCl}(7 \mathrm{M})$ was added to the $2 \mathrm{ml}$ tube and mixed gently, and the entire solution was transferred to extraction column tubes (GP ${ }^{\mathrm{TM}}$ Column, VIOGENE, USA) and subsequently centrifuged at $8000 \mathrm{~g}$ for 1 min. After discarding the flow-through, $500 \mu \mathrm{f}$ of $70 \%$ EtOH was added and centrifuged at 8000 $g$ for $5 \mathrm{~min}$. This step was repeated twice. Finally, the extraction columns were transferred to new $1.5 \mathrm{ml}$ Eppendorf tubes and incubated at $37{ }^{\circ} \mathrm{C}$ for $15 \mathrm{~min}$. Preheated $\left(60{ }^{\circ} \mathrm{C}\right) \mathrm{TE}$ buffer $(50$ $\mu 1)$ was used for the final extraction step, and the column was centrifuged at 13,000 $\mathrm{g}$ for $3 \mathrm{~min}$. All DNA samples were kept at $-20{ }^{\circ} \mathrm{C}$ until further use

\section{Restriction Fragment Length Polymorphism analysis of Symbiodinium clades}

Initially to assess the diversity of Symbiodinium at clade level, DNA from1913 coral samples were analyzed by Restriction Fragment Length Polymorphism (RFLP) technique. Both Nuclear large-subunit ribosomal (nlsr) DNA and nuclear small-subunit ribosomal (nssr) DNA were used to investigate the clade diversity. The polymerase chain reaction (PCR) amplification of nlsrDNA and nssrDNA was modified from a previously published protocol (Chen et al. 2005). 
182 The DNA concentration was adjusted to $30 \sim 50 \mathrm{ng} \mu \mathrm{l}^{-1}$ for each PCR reaction, with a final

183 concentration of $0.2 \mathrm{mM}$ dNTP, $0.5 \mu \mathrm{M}$ primer, 1 x PCR buffer with $1.5 \mathrm{mM} \mathrm{MgCl}$, and 2.5 units

184 of $\mathrm{Taq}$ DNA polymerase (Invitrogen ${ }^{\mathrm{TM}}$, USA). PCR was performed by pre-denaturation at $95^{\circ} \mathrm{C}$

185 for 1 min followed by 30 cycles of denaturation at $94{ }^{\circ} \mathrm{C}$ for $45 \mathrm{~s}$, annealing at $50^{\circ} \mathrm{C}$ for $45 \mathrm{~s}$, and 186 extension at $72{ }^{\circ} \mathrm{C}$ for $2 \mathrm{~min}$. The final extension was performed at $72{ }^{\circ} \mathrm{C}$ for 6 min. The $\mathrm{D} 1$ and 187 D2 regions of Symbiodinium nlsrDNA were first amplified with the primer set (D1/D2 F: 5'-CCT 188 CAG TAA TGG CGA ATG AAC A-3' and D1/D2 R: 5'-CCT TGG TCC GTG TTT CAA GA-3') 189 (Loh et al. 2001), and the PCR products were then characterized using restriction enzyme Rsa I. 190 The nssrDNA of Symbiodinium was amplified using a host-excluding primer pair (ss5z: 5'-GCA 191 GTT ATA RTT TAT TTG ATG GTY RCT GCT AC-3' and ss3z: 5'-AGC ACT GCG TCA GTC 192 CGA ATA ATT CAC CGG-3'), and the products were characterized using restriction enzymes 193 Sau3A I and Taq I (Rowan \& Powers 1991). All enzymes used for RFLP were purchased from 194 MBI (Fermantas, Italy). Digested nlsrDNA PCR products were separated at $150 \mathrm{~V}$ by vertical gel 195 electrophoresis for $3.5 \mathrm{~h}$ on a $5 \%$ acrylamide gel (30\% acrylamide/bis-acrylamide (37.5:1), $10 \mathrm{x}$ 196 TBE buffer, 25\% ammonium persulfate, and TEMED). This was done to increase the clarity of 197 the nlsrDNA band pattern, which sometimes was not clear on the agarose gels. The digestion 198 products of nssrDNA PCR-RFLP were separated by gel electrophoresis on a 3\% agarose gel for $1993.5 \mathrm{~h}$ at $50 \mathrm{~V}$.

200 DGGE analysis of Symbiodinium types

201 To assess the Symbiodinium diverstiy at type level, representative DNA samples from 202 different band patterns from the RFLP analysis were picked and subjected to ribosomal internal 203 transcribed spacer 2 region (ITS2) amplification using primers ITSintfor2: 5'-GAA TTG CAG 
205 GAT CCA TAT GCT TAA GTT CAGC GGG T-3' (Lajeunesse and Trench 2000). Each $50 \mu 1$

206 PCR reaction consisted of $50 \mathrm{ng}$ genomic DNA, 1x PCR Buffer, $2.5 \mathrm{mM} \mathrm{MgCl} 2,0.4 \mathrm{mM}$ dNTPs, $2070.4 \mu \mathrm{M}$ of each primer, and 2 units of Taq polymerase (Invitrogen, USA). PCR was run on a Px2 208 thermal cycler (Thermo Scientific, USA) with touch-down PCR (LaJeunesse 2002) to ensure 209 specificity. The initial denaturing period was at $92{ }^{\circ} \mathrm{C}$ for $3 \mathrm{~min}$, followed by 20 cycles of $30 \mathrm{~s}$ at $21092{ }^{\circ} \mathrm{C}$, and annealing conditions from $62{ }^{\circ} \mathrm{C}$ were decreased by $0.5^{\circ} \mathrm{C}$ to the final annealing 211 temperature of $52{ }^{\circ} \mathrm{C}$ for $30 \mathrm{sec}$ at $72{ }^{\circ} \mathrm{C}$. Once the annealing temperature reached $52{ }^{\circ} \mathrm{C}$, it was 212 maintained at that level for another 20 cycles, followed by a final extension period of $10 \mathrm{~min}$ at $21372{ }^{\circ} \mathrm{C}$. Each PCR product was loaded onto an acrylamide denaturing gradient gel (45-80\%) and 214 then electrophoresed at 115V for $15 \mathrm{~h}$ using a CBS Scientific system (Del Mar, CA, USA). Gels 215 were stained with SYBR Green (Molecular Probes, Eugene, OR, USA) for $15 \mathrm{~min}$ and 216 photographed for further analysis. Band patterns were confirmed by sequencing the cut bands 217 from the DGGE gel.

Coral community data

Historical coral community data for NPP OL was obtained from various published reports. Although it is difficult to compare historical data with the present data due to a change in methodology over the years, it is still possible to get an idea of how the community readjusted or 222 redistributed over time. For 1986, we used community data previously published (Dai 1988, Dai et al. 1998) that was obtained with quadrat sampling to estimate the percent cover of each species at NPP OL. We compared this with the data from our own 2009-2010 survey using a $20 \mathrm{~m}$ 
226 in 1986 and 1995 and compared them with 2010 photographs obtained from the same locations.

227 Due to problems in comparing the data, it was not possible to compare them quantitatively, so we 228 only show the pictorial comparison of how some coral genera have been replaced over time.

\section{Historical and present day environmental data}

230 Seawater temperature data from 1982-1992 were obtained from the Taiwan Power

231 Company's eleven-year ecological survey of waters adjacent to the nuclear power plant. Data 232 after 1995 was obtained from different sites recorded with temperature loggers (HOBO 233 Pendant $^{\mathrm{TM}}$, USA).

To analyze the relationship between Symbiodinium diversity trend and environmental 235 parameters, data was also obtained as time series for sea surface temperature (SST which 236 included; average temperature -Tavg, summer average temperature-Ts, winter average 237 temperature-Tw), chlorophyll a (Cha-a), photosynthetically active radiation (PAR) and diffuse 238 attenuation coefficient (Kd) over the time period 2002-2010 (at $4 \mathrm{~km}$ spatial resolution) from 239 MODIS/aqua interface of the Giovanni online data system, developed and maintained by the 240 NASA GES DISC.

For contour diagram of the seasonal seawater temperature across the Nanwan bay, 242 seawater was collected using CTD at various sites between 2008-2010. The exact positions of 243 sampling sites were located by global position system (GPS). The measurements of temperature 244 were carried out with CTD instrument (Sea-Bird Model 19 plus) by the EPA/ROC (Taipei) on 245 fishing boats. The precision for temperature was $\pm 0.05^{\circ} \mathrm{C}$. After the data output from CTD, 246 contour maps were created using Surfer (Windows). 
The nonparametric Mannut from CTD, contour maps were created using Surfer

249 (Windows). ng sites were located by global position system (GPS). The mes in seawater 250 temperatures between the two depths at NPP OL and between NPP OL and different sites (WLT, 251 MBT, STZ, and IL). To compare Symbiodinium clade distributions, the Chi-Square test and 252 single-factor between-subjects ANOVA (independent samples) were used. The ANOVA results 253 were plotted as one-way diamond mean comparisons to see the differences in Symbiodinium 254 composition at different sites between $3 \mathrm{~m}$ and $7 \mathrm{~m}$ and for total Symbiodinium $\mathrm{C}$ and 255 Symbiodinium D composition at NPP OL (3 $\mathrm{m}$ and $7 \mathrm{~m})$. The horizontal dashed line in the 256 diamond plot is the overall mean (i.e., grand mean). The line through the center of each diamond 257 is the group mean. The top and bottom diamond vertices are the respective upper and lower $95 \%$ 258 confidence limits (CI) about the group mean.

To understand the relationship between the environmental data, coral host and 260 Symbiodinium at different sites and depths, similarity (Bray-Curtis) in the host and symbiont data 261 (presence/absence) was analyzed using Principle Coordinate Analyses (PCO) and ANOSIM. The 262 host and symbiont similarity matrices were analyzed for a significant relation (Spearman rho, rho $263 \approx 0$ indicates no relation is found, rho $=1$ indicates a perfect relation) using RELATE. Distance264 based analysis on a linear model (distLM) was used to model the relationship between the 265 symbiont dissimilarity data and the environmental variables. To include the host effect on the 266 symbiont matrix, PCO1 and PCO2 of the host presence/absence data (HPCO1 and HPCO2 for 267 continued reference) were added as covariates to the environmental data matrix in subsequent 268 linear regression data analyses (see Tonk et al. 2013b). In the distLM, marginal tests assessed the 
269 importance of each variable separately and a forward search of the optimal fit based on an 270 adjusted $\mathrm{R}^{2}$ was used by sequentially adding environmental variables. The data was visualized 271 with distance based redundancy analyses (dbRDA) ordination plots. Vector overlays using the 272 environmental data and symbiont data separately as predictor variables (drawn as multiple partial 273 correlations) were applied to visualize the effect, strength and direction of the different variables

274 in the ordination plots. The symbiont distributions on a clade and type level were explained with 275 environmental data (normalized), in which the collected host information included either on a 276 species level or genus level. All symbiont and host data was transformed to relative abundance.

\section{Results}

285 the nuclear power plant, the average seawater temperature $\left(26.0^{\circ} \mathrm{C}\right)$ was the same at all locations where seawater temperature data could be obtained. However, after construction of the nuclear 287 power plant in 1984 , the average seawater temperature at NPP OL was consistently $2.0-3.0^{\circ} \mathrm{C}$ 288 higher (Fig. 2 A) than adjacent locations. Monthly and daily average seawater temperatures 289 showed a similar trend (Fig. 2 B) (also see Keshavmurthy et al. 2012, Hsu et al. 2012). NPP OL 
290 seawater temperatures at the $3 \mathrm{~m}$ depth were significantly higher than $7 \mathrm{~m}$ depths $(\mathrm{p}<0.0001)$.

291 The thermal effluent in NPP OL is restricted to the water column above $3 \mathrm{~m}$, and the temperature 292 differential does not influence depths below 7m. Also, NPP OL experiences daily fluctuation of $2938.0-10.0{ }^{\circ} \mathrm{C}$ (for 6 hours) due to upwelling as a result of internal tides and waves generated at 294 Luzon Strait, which directly affects the seawater present in Nanwan Bay in Kenting (Chen et al. 295 2004). Differences between daily average seawater temperatures at NPP OL and two relatively 296 distant control sites (WLT and IL) were statistically significant (Mann-Whitney test, $p<0.0001$ ), 297 whereas those between NPP OL and two closer sites (MBT and STZ) were not statistically 298 significant (Mann-Whitney test, $p$ >0.001) (see also Keshavmurthy et al. 2012). Contour 299 diagram of the seawater temperature in Nanwan showed consistent presence of hot water plume 300 near the NPP OL irrespective of the seasons (Fig 3).

301 Coral - Symbiodinium associations From the Restriction Fragment Length Polymorphism (RFLP) data, the dominant 303 Symbiodinium clade associated with corals at eight sites in Kenting was Symbiodinium clades C 304 305 (Fig. 4A). Our analysis of the Symbiodinium clade in coral genera at NPP OL showed that heattolerant Symbiodinium clade D was dominant in corals at the $3 \mathrm{~m}$ depth (Fig. 4A, B). Coral 306 genera at the $7 \mathrm{~m}$ depth, however, were associated with Symbiodinium clade $\mathrm{C}$ at all study

307 locations including NPP OL (Fig. 4A, B, Fig. 5). In contrast, Symbiodinium clade C was 308 dominant at $7 \mathrm{~m}$ (199 out of 234 samples, 85\%, Chi-square test: $\mathrm{X}_{(0.01)}$ : 0.0001) (Fig. 4A, B), 309 with only five genera having a mixed composition of Symbiodinium clade C and Symbiodinium 310 clade D (Fig. 4A, B). The difference in Symbiodinium clade D clade between $3 \mathrm{~m}$ and $7 \mathrm{~m}$ at NPP 311 OL was significant (one way ANOVA; $\mathrm{p}=0.001$ ). A similar significant difference was also 
312 observed in the presence of Symbiodinium clade C between $3 \mathrm{~m}$ and $7 \mathrm{~m}$ at NPP OL (Fig. 5).

Based on the results form ITS2 DGGE, the Symbiodinium types found in corals hosts

314 belonged to type D1a (mainly found in coral hosts present in NPP OL 3m) and types C1, C3, 315 C21a and C15. Since we have utilized both RFLP and DGGE for analysis, to avoid confusion, 316 throughout the text we will follow the nomenclature used for DGGE and discuss the results using 317 DGGE ITS2 Symbiodinium types.

318 Of sixteen genera (Fig. 4), twelve genera hosted significantly more SymbiodiniumD type 319 D1a at NPP OL 3m in response to thermal stress and mostly or only Symbiodinium types C1, C3, $320 \mathrm{C} 21 \mathrm{a}$ and C15 at NPP OL 7m (Acropora, Cyphastrea, Goniastrea, Isopora, Platygyra, Favites, 321 Pocillopora, Acanthastrea, Leptoria, Montastraea), except for Pavona and Montipora which had 322 Symbiodinium types $\mathrm{C} 1$ and $\mathrm{C} 15$ respectively as the dominant clade at both NPP OL $3 \mathrm{~m}$ and 7 $323 \mathrm{~m}$. The genus Porites was specifically associated with Symbiodinium type C15 at all locations, 324 and the weedy genus Galaxea was associated with Symbiodinium type D1a at all locations and 325 rarely hosted Symbiodinium type C1 (Fig. 4B, also see Fig. S1). Finally, two genera, Seriatopora 326 and Stylophora, were associated with Symbiodinium C type C1 and were entirely absent at the 327 thermally stressed NPP OL site (Fig. 4C, see Fig. S1). At sites other than NPP OL, the degree to which competent genera hosted Symbiodinium 329 clade D or a combination of Symbiodinium clade D and clade C varied considerably. No 330 Acropora samples were observed to do so, Pocillopora and Platygyra did so at only one other 331 location, and other genera (Cyphastrea, Goniastrea, Isopora, Pavona, Acanthastrea, Leptoria, 332 Montastraea) did so at multiple locations. However, genera Cyphastrea, Isopora, Pavona, and 333 Goniastrea routinely hosted only Symbiodinium clade D at non-thermally stressed locations 
334 (Table S1). Species level comparisons among NPP OL (warm water influence) and WLT and 335 SJW (sites without warm water influence) also showed that the $3 \mathrm{~m}$ site at NPP OL was 336 dominated by Symbiodinium clade D, while at other sites and at NPP OL $7 \mathrm{~m}$ depths the 337 dominant Symbiodinium belonged to clade C (Fig. 4C, Table S1, Fig. S1A, B).

\section{Coral Community}

A comparison of the 1986 coral community at $3 \mathrm{~m}$ depths at NPP OL to the 2010 340 community showed a difference in the dominant species (Table 1). While Acropora $(24.20 \%$ of 341 total coral cover) and Montipora (33.69\% of total coral cover) dominated the shallow waters in 3421986 , Montipora (21.70\% of total coral cover) and Galaxea (21.20\% of total coral cover) 343 dominated the 2010 coral community. Other genera (Favites, Pavona, and Porites) that were < $3442 \%$ of the total abundance in 1986 had increased their relative abundance by 2010 (Table 1). By

3452010 , the presence of Acropora had been greatly reduced (0.70\%) and Seriatpora and Stylophora 346 were completely absent at $3 \mathrm{~m}$ depths at NPP OL (Fig. 6, Fig. 7, Table 1). Results from DistLM 347 and Bray-Curtis similarity resemblance analysis on the coral community presence or absence at 348 different locations also showed dominance of Galaxea at NPP OL 3m. (Fig, 8C)

Relationship between sites, Symbiodinum distributions and environmental factors

350

351 In terms of seawater temperature differences, there was a clear difference between NPP OL $3 \mathrm{~m}$ 352 and other sites with NPP OL $3 \mathrm{~m}$ always appearing as an out group in the analysis (Fig. 8, Table 353 2). Due to its proximity with NPP OL, site TS also grouped with NPP OL 3m in DistLM analysis 354 (Fig. 8A). Analysis also showed that several environmental parameters (Tavg - long term from 355 2002-2010) and Tsd), including the host, were responsible for driving the symbiont community. 356 There was a clear pattern in terms of symbiont distribution (both on a cladal and type level) and 
357 NPP OL 3m was significantly different in its symbiont composition (Fig. 8A, B, Table 2). The

358 distribution of different general among the sites reflected the results of the present day coral 359 community data. Genus Galaxea was mainly clustered with NPP OL 3m (Fig. 8C).

\section{Discussion}

This study observed the effect of chronically elevated seawater temperatures on the 362 composition of coral hosts and coral-Symbiodinium in sixteen coral genera between NPP OL and 363 adjacent control sites. Our results clearly showed the presence of more Symbiodinium clade D at 364 NPP OL (3 m) compared with other sites, and Symbiodinium clade C was dominant at $7 \mathrm{~m}$ at all 365 locations including NPP OL (Figs. 3, 4). Our results suggest that the present day coral host 366 hSymbiodinium combinations could be due to the long-term input of hot water. This can be seen by the dominance of Symbiodinium clade D in the coral hosts present near the NPP OL site. We posit that the observed composition of Symbiodinium associated with the corals at NPP OL ( $3 \mathrm{~m})$ might have occurred over years of acclimatization of individual hosts and Symbiodinium clades exposed to higher and more variable temperatures and adaptation through selection and parallel evolution of resistant host-Symbiodinium combinations. A reef with a higher abundance of

372 Symbiodinium clade D-dominated holobionts is assumed to have a higher tolerance to thermal 373 stress (Ortiz et al. 2012). Alternatively, the present coral-Symbiodinium composition at NPP OL 374 (3 m) might be a result of the adaptive plasticity of competent coral hosts and Symbiodinium 375 either separately or in combination over time. We suggest that the only plasticity that predictably 376 enhances fitness and is most likely to facilitate adaptive evolution on ecological timescales in 377 new environments is that which places populations close enough to a new phenotypic optimum 378 for directional selection to act (Ghalambor et al. 2007). Long-term environmental standing of 
379 above average seawater temperatures at NPP OL $3 \mathrm{~m}$ and other factors such as nutrient input into

380 the Nanwan might also be the reason for the present day structuring of the coral host and 381 Symbiodinium diversity. However, from our analysis, there was a clear relationship between the 382 environmental factors and distribution of Symbiodinium clades. The sampling sites at Nanwan, 383 although not very separated from each other, are different in the way they are affected mainly by 384 seawater temperature (Hsu et al. 2012). This is both due to the physical differences in 385 temperature fluctuations, internal waves, upwelling and the constant out put of hot water into the 386 NPP OL site and surrounding areas (Hsu et al. 2012, Keshavmurthy et al. 2012). Such factors 387 have induced the present day Symbiodinium distribution in those coral hosts present at different 388 sites in Nanwan.

In studies conducted to date, the impact of thermally tolerant Symbiodinium has largely 390 been documented at the colony scale, and the consequences at the population and community 391 level within an ecosystem context are unknown (Ortiz et al. 2012). We show that at community 392 level, Symbiodinium type D1a was dominant in 12 of 16 genera living at the $3 \mathrm{~m}$ depth at NPP 393 OL (Fig. 4C, Fig. S1), whereas the same 12 genera at the $7 \mathrm{~m}$ depth at NPP OL were associated 394 only with Symbiodinium types C1, C3 and C21 (Fig. 4C, Fig. S1). The depth-related stratification 395 in the clade association at NPP OL might be due to decades of constant seawater temperature 396 elevation $\left(2.0-3.0^{\circ} \mathrm{C}\right)$. At generic level, most of the corals at NPP OL $3 \mathrm{~m}$ hosted solely 397 Symbiodinium type D1a. Two genera Montipora and Porites associated mostly or solely with 398 Symbiodinium type C15. While the strategy of dominant 12 genera was their capacity to associate 399 with a stress-tolerant Symbiodinium clade, the strategy followed by Porites could be a result of a 400 stress-resistant mechanism. Genus Galaxea was abundant and associated with Symbiodinium type 401 D1a at almost every site where it was collected, indicating that Galaxea is able to tolerate 
402 disturbances and thrive in perturbed environments. From the above observations we believe that 403 such difference, despite constant warm water and a large daily fluctuation in the seawater 404 temperature (Chen et al. 2004), is due to the ability of coral-Symbiodinium combinations to thrive 405 or the host itself to be able to survive in such conditions. And because of inability of some genera 406 to host Symbiodinium type D1a or any other resistant Symbiodinium combination, Stylophora and 407 Seriatopora were absent from $3 \mathrm{~m}$ at NPP OL.

408 Many previous studies have shown that the shuffling of Symbiodinium and/or host 409 resistance mechanisms can confer resistance in corals to environmental stress. From the 410 observations in this study and a recent study (Keshavmurthy et al. 2012), we suggest there is the 411 possibility of a strategy shift (Done 1999) in corals present in NPP OL or other sites, although we 412 could not demonstrate the shuffling of Symbiodinium in corals per se. NPP OL populations at 3 $413 \mathrm{~m}$ would represent stressed populations that have evoked a dominance of stress tolerant 414 Symbiodinium type D1a as one option during their adjustment to the upper limit of their thermal 415 range. There are at least two other alternative explanations, however. First, Symbiodinium type 416 D1a may be an opportunistic type (see Stat and Gates 2011) that occupies compromised coral 417 hosts, resulting in a less than optimal symbiosis and reduced rates of host growth. In this case, 418 NPP OL corals at $3 \mathrm{~m}$ are stressed and populated by less optimal varieties of Symbiodinium. 419 Although corals associated with Symbiodinium type D1a may benefit in the short term by 420 surviving bleaching, there are clearly trade-offs in terms of fitness that may have major 421 implications for the long-term growth and survival of coral reefs (Stat and Gates 2011, also see 422 Oritz et al. 2013), thereby negatively affecting the competitive ability of corals (Baker et al. 423 2013). For example, the association of A. tenuis juveniles with Symbiodinium D resulted in 424 higher metabolic costs and lower physiological tolerances (Abrego et al. 2008). Second, new 
425 host-Symbiodinium combinations could arise as a result of directional selection where all 426 combinations of host-Symbiodinium arrive in the shallows at NPP OL but only those with 427 significant associations with Symbiodinium D survive. The latter explanation would be a 428 consequence of the fact that NPP OL is open to populations not experiencing the same levels of 429 thermal stress, and hence the resulting composition of Symbiodinium is a consequence of active 430 selection for the Symbiodinium that occupy these coral genera and not shuffling per se. However, 431 Baker et al. (2013) have posited that acute disturbances or long-term environmental conditions 432 are not sufficient to explain the composition of symbiont communities and their dynamics in any 433 given location. The trend seen in the symbiont composition can be more explained by physical 434 factors such as daily seawater temperature fluctuations as a result of tidal oscillations or internal 435 waves induced upwelling, which act as acute and chronic stressors. This can be one explanation 436 for the presence of dominant Symbiodinium type D1a in the coral hosts in NPP OL 3m. Constant 437 hot water output and daily temperature fluctuations up to $10^{\circ} \mathrm{C}$ (Chen et al. 2004) in the NPP OL 438 site might have allowed Symbiodinium type D1a to be maintained at relatively high levels at NPP 439 OL 3m. This also shows that Symbiodinium type D1a not necessarily be always opportunistic, 440 thermally tolerant and transient during stress conditions, but also can be capable of long-term 441 persistence on reefs with favorable conditions (Baker et al. 2013). All the hypotheses that we 442 have put forth above should be considered as alternatives to explain the trend of existing coral443 Symbiodinium associations at warm water-affected locations at NPP OL.

In the case of coral hosts, there were considerable changes in the types of dominant coral 445 at $3 \mathrm{~m}$ while the composition at $7 \mathrm{~m}$ at NPP OL did not change over the years (Table 1, Fig. 6, 446 Fig. 7). The present day framework of the NPP OL community could be due to a strategy shift 447 between Symbiodinium and coral stages, where both transient and continual states exist in the 
448 composition of associated Symbiodinium clades and coral genera. In the case of Kenting reefs,

449 strategy shifting exists not only between the two water depths at NPP OL but also between the 450 sites (see Kuo et al. 2012). Form the long term satellite seawater temperature data, the averages 451 of temperature at NPP OL $3 \mathrm{~m}$ is similar to the WLT site, however, the analysis results showed 452 otherwise, with TS $7 \mathrm{~m}$ as more similar to NPP OL $3 \mathrm{~m}$ indicating some other factors in addition to 453 the above mentioned environmental factors influencing the patterns seen in the host as well as 454 Symbiodinium distributions. But the distLP analysis suggested that the environmental data more 455 than sufficiently explains the variation seen in the symbiont community. The other explanation 456 for the difference seen in the symbiont distribution might be the differences in the host 457 distribution among the sites. But, our sampling design made sure to sample hosts as uniform as 458 possible at all sites, except in such cases where a particular host was absent and could not be 459 sampled. As mentioned above, apart from the environmental factors that were included in the 460 analysis,

462 at Kenting might have been a result of populations developing tolerance to along-shore gradients 463 of environmental factors, including temperature and pollution. At scales of less than $1 \mathrm{~km}$, 464 differentiation can occur over short, vertical stress gradients along horizontal gradients of wave 465 exposure covering a few hundred meters. Variations in seawater temperatures and anthropogenic 466 changes in Kenting might have led to adaptive divergence in physiological traits among 467 populations distributed across a variety of scales. Studies have shown that human and natural 468 disturbances are similar at all the sites represented in this study (Meng et al. 2008; Kuo et al. 469 2012). Apart from long-term hot water perturbations at NPP OL, other areas are not much 470 different in terms of exposure to stress at Kenting. While coral communities at other Kenting sites 
471 show considerable changes over time (Kuo et al. 2012), the coral presence at NPP OL is still 472 diverse and there is no evidence of a shift in the community from corals to algae. Studies have 473 suggested that historical effects play an important role in determining the fate of individuals, 474 populations, and communities (from Marshall and Baird 2000). In case of corals, a historical 475 thermal exposure can influence their thermal tolerance (see Howells et al. 2013), and this could 476 be through acclimatization and selection for tolerant genotypes. Also, over longer periods of time 477 (between generations), selection may drive heritable changes in the mean phenotype, but in long478 lived individuals such as corals the genetic adaptation might be slow and occur over decadal time 479 scales (van Oppen et al. 2011; Császár et al. 2010; Hoegh-Guldberg et al. 2007; Aitken et al. 480 2008). However, genotypic variation among individuals allows the species to persist through the 481 expansion of genotypes better suited for a new climate (Richter et al. 2012; also see Kramer et al. 482 2010). van Oppen et al. (2011) suggested that somatic mutation during asexual reproduction 483 could aid corals in evolution and adaptation (see also Fautin 1997; Buddemeier et al. 1997). 484 Evolution within mitotic cell lineages, both in the coral host and Symbiodinium (Correa et al. 485 2010), might play a role in the adaptation of corals to climate change.

\section{Conclusions}

Our work and a previous study (Berkelmans and Van Oppen 2006) show that even if 488 several coral species could withstand temperature increases beyond $1.0-1.5{ }^{\circ} \mathrm{C}$, the surviving coral species may not be sufficient to maintain healthy reefs. Due to long-term acclimatization, community level resistance to perturbations (in our case, seawater temperature) is possible

491 through association with stress resistant Symbiodinum clade D. Acclimatization is an important 492 strategy by which individuals can adjust phenotype to perform more optimally under changed 
493

494

495

496

497

498

499

500

501

502

503

504

505

506

507

508

509

510

511

512

513

514

515

environmental conditions.

Studies have shown that in coral reefs the process of local adaptation and acclimatization to high average temperatures and recurrent thermal stress is possible (Rowan et al. 1997; Marshall and Baird 2000; Brown et al. 2002; Howells et al. 2011; 2013). There are limits to acclimatization, however, which are set by tradeoffs at various structural and functional levels that ultimately constrain the width of the thermal range of a given species (see Doney et al. 2012). These constraints highlight the limits of acclimatization, which ultimately results in shifting community composition as tolerance thresholds in the more vulnerable species of a given community are exceeded. Laboratory research has shown that genetic variation for plasticity exists (Barshis et al. 2010; Császár et al. 2010) and heritable plasticity can respond to artificial selection (Nussey et al. 2005). Given that corals are exposed to long-term anthropogenically driven environmental change (Hoegh-Guldberg 1999; Hoegh-Guldberg et al. 2007), it is imperative to obtain a better understanding of how natural selection acts on plasticity under altered levels of environmental variation in the wild (Nussey et al. 2005). Understanding the limits of these combinations will allow us to understand why some corals are 'winners' and others are 'losers' during the early stages of rapid anthropogenic climate change (see Loya et al. 2001). To some extent, the development of an optimal combination of coral hosts (from around 800 species) and Symbiodinium (over 100 distinct genetic varieties from 4 major clades) is a complex (Goulet 2006) and stochastic process somewhat like a lottery (Jones 2008). Parmesan and Yohe (2003) provided evidence of ecosystems altered by climate change. Our results suggest that corals assemblages and their symbionts exposed to warmer waters are already undergoing alteration. Our data also suggest that not all coral species in a given community have the ability to acclimatize to survive in warmer water. Current evidence suggests that natural adaptation 
516 within coral populations is unlikely to occur quickly enough to keep up with rapid changes in 517 ocean temperatures, and although shuffling Symbiodinium clades could play an important role in 518 extending the physiological performance of a coral species, this might not be the case at the 519 community level, resulting in the loss of some species over time (Fig. 6). If the present trend of 520 ocean warming and change continues, we might be looking at unsustainable restructuring of coral 521 assemblages in a given coral community (Fig. 6), which in turn would cause irreversible damage 522 to coral reef ecosystems. 


\section{ACKNOWLEDGEMENTS}

525 We thank Jay Wei for field assistance and Chen-Ju Lai for Symbiodinium phylotyping. Research 526 permits were granted by Kenting National Park and Tai-Power Plant. This is Coral Reef

527 Evolutionary Ecology and Genetics Group, Biodiversity Research Centre, Academia Sinica 528 contribution No. XX. 
530

531

532

533

534

535

536

537

538

539

540

541

542

543

544

545

546

547

548

549

550

551

552

553

554

555

556

557

558

559

560

561

562

563

564

565

566

567

568

569

570

571

572

573

\section{REFERENCES}

Abrego D, Ulstrup K, Willis B, van Oppen M. 2008. Specieseciesn M. 2008. SpeciesSpeciesciespecendosymbionts and coral hosts define their bleaching response to heat the light stress Proceedings of the Royal Society B-Biological Sciences 275:22732282.

Aitken SN, Yeaman S, Holliday JA, Wang T, Curtis-McLane S. 2008. Adaptation, migration or extirpation: climate change outcomes for tree populations. Evolutionary Applications 1:95tiona

Ayre D, Hughes T. 2004. Climate change, genotypic diversity and gene flow in reef-building corals. Ecology Letters 7:273-278.

Baird AH, Bhagooli R, Ralph PJ, Takahashi S. 2009. Coral bleaching: the role of the host. Trends in Ecology and Evolution 24: 16-20.

Baker A. 2001. Ecosystems: reef corals bleach to survive change. Nature 411:765 2001

Baker A, Starger C, McClanahan T, Glynn P. 2004. Coral reefs: corals' adaptive response to climate change. Nature 430:741.

Baker AC, McClanahan TR, J SC, K BR. 2013. Long-term monitoring of algal symbiont communities in corals reveals stability is taxon dependent and driven by site-specific thermal regime. Marine ecology progress series 479:85ecol

Barshis DJ, Stillman JH, Gates RD, Toonen RJ, Smith LW, Birkeland C. 2010. Protein expression and genetic structure of the coral Porites lobata in an environmentally extreme Samoan back reef: does host genotype limit phenotypic plasticity? Molecular Ecology 19:1705r Ecol

Bellantuono AJ, Hoegh-Guldberg O, Rodriguez-Lanetty M. 2011. Resistance to thermal stress in corals without changes in symbiont composition. Proceedings of the Royal Society Biological Sciences 279:1100-1107.

Bhagooli R, Yakovleva I. 2004. Differential bleaching susceptibility and mortality patterns among four corals in response to thermal stress. Symbiosis 37:121 is Di

Bell G. 2012. Evolutionary rescue and the limits of adaptation. Philosophical Transactions of the Royal Society B-Biological Sciences 368:20120080.

Berkelmans R, Van Oppen MJH. 2006. The role of zooxanthellae in the thermal tolerance of corals: A "nugget of hope" for coral reefs in an era of climate change. Proceedings of the Royal Society - Biological Sciences 273:2305gs of

Brown B. 1997. Adaptations of reef corals to physical environmental stress. Advances in Marine Biology 31:221s in

Brown B, Downs C, Dunne R, Gibb S. 2002. Exploring the basis of thermotolerance in the reef coral Goniastrea aspera. Marine Ecology Progress Series 242:119colog

Buddemeier RW, Fautin DG, Ware JR. 1997. Acclimation, adaptation and algal symbiosis in reefbuilding scleractinian corals. In Coelenterate Biology: Proceedings of the Sixth International Congress of Coelenterate Biology; Nationaal Natuurhistorisch Museum: Leiden, The Netherlands 3Muse

Chen C-T, Wang B-J, Hsing L-Y. 2004. Upwelling and degree of nutrient consumption in Nanwan Bay, Southern Taiwan. Journal of Marine Science and Technology 12:442-447.

Chen C, Wang J-T, Fang L-S, Yang Y-W. 2005. Fluctuating algal symbiont communities in Acropora palifera (Scleractinia: Acroporidae) from Taiwan. Marine Ecology Progress 
574

575

576

577

578

579

580

581

582

583

584

585

586

587

588

589

590

591

592

593

594

595

596

597

598

599

600

601

602

603

604

605

606

607

608

609

610

611

612

613

614

615

616

617

618

619

Series. 295:11333olo

Chiou WD, Cheng LZ, Ou HC. 1993. Relationship between the dispersion of thermal effluent and the tidal current in the waters near the outlet of the third nuclear power plant in southern Taiwan. Journal of Fisheries Society of Taiwan 20:207 of F

Coles SL, Brown BE. 2003. Coral bleaching - capacity for acclimatization and adaptation. Advances in Marine Biology 46:183s in

Correa AMS, Correa AMS, Baker AC, Baker AC. 2010. Disaster taxa in microbially mediated metazoans: how endosymbionts and environmental catastrophes influence the adaptive capacity of reef corals. Global Change Biology 17:68 Cha

Császár NBM, Ralph PJ, Frankham R, Berkelmans R, van Oppen MJH. 2010. Estimating the potential for adaptation of corals to climate warming. PLOS ONE 5:e9751.

Dai C-F. 1988. Community ecology of corals on the fringing reefs of southern Taiwan. PhD thesis. Yale University.

Dai C-F, Chen Y-T, Kuo K-M, Chuang C-H. 1998. Changes of coral communities in Nanwan Bay, Kenting National Park: 1987nal ParJournal of National Park 8:79al of National Park987munities in Nanwa

Done T. 1999. Coral community adaptability to environmental change at the scales of regions, reefs and reef zones. American Zoologist 39:66-79.

Donelson JM, Munday PL. 2012. Thermal sensitivity does not determine acclimation capacity for a tropical reef fish. Journal of Animal Ecology doi: 10.1111/j.1365-2656.2012.01982.x

Doney SC, Ruckelshaus M, Emmett Duffy J, et al. 2012. Climate Change Impacts on Marine Ecosystems. Annual Review of Marine Science 4:111 Re

Fan KL. 1991. The thermal effluent problems of three nuclear power plants in Taiwan. In: Oceanography of Asian Marginal Seas, (ed Takano K), Elsevier Oceanography Series, Amsterdam, The Netherlands 54:393-403.

Farde PR, Englebert N, Faria J, Visser PM, Bak RPM. 2008. Distribution and photobiology of Symbiodinium types in different light environments for three colour morphs of the coral Madracis pharensis: is there more to it than total irradiance? Coral Reefs 27: 913-925.

Fautin DG. 1997. Cnidarian reproduction: assumptions and their implications. In Coelenterate

Biology: Proceedings of the Sixth International Congress of Coelenterate Biology; Nationaal Natuurhistorisch Museum: Leiden, The Netherlands, 151-162.

Ferrara GB, Murgia B, Parodi AM, et al. 2006. The assessment of DNA from marine organisms via a modified salting-out protocol. Cellular \& molecular biology letters $11: 155 \mathrm{r} \& \mathrm{~m}$

Fitt W, Brown B, Warner M, Dunne R. 2001. Coral bleaching: interpretation of thermal tolerance limits and thermal thresholds in tropical corals. Coral Reefs 20:51-65.

Ghalambor CK, McKay JK, Carroll SP, Reznick DN. 2007. Adaptive versus non-adaptive phenotypic plasticity and the potential for contemporary adaptation in new environments. Functional Ecology 21:394nal E

Gittenberger A, Hoeksema BW. 2006. Phenotypic plasticity revealed by molecular studies on reef corals of Fungia (Cycloseris) spp. (Scleractinia: Fungiidae) near river outlets. Contributions to Zoology 75:195-201.

Goulet T. 2006. Most corals may not change their symbionts. Marine Ecology Progress Series 321:1 Ec

Hennige S, Smith D, Walsh S. 2010. Acclimation and adaptation of scleractinian coral communities along environmental gradients within an Indonesian reef system. Journal of Experimental Marine Biology and Ecology 391:143-152. 
620 Hoegh-Guldberg O. 1999. Climate Change, Coral Bleaching and the Future of the World's Coral

621

622

623

624

625

626

627

628

629

630

631

632

633

634

635

636

637

638

639

640

641

642

643

644

645

646

647

648

649

650

651

652

653

654

655

656

657

658

659

660

661

662

663

664

665 Reefs. Marine and Freshwater Research 50:839-866.

Hoegh-Guldberg O, Mumby PJ, Hooten AJ, et al. 2007. Coral reefs under rapid climate change and ocean acidification. Science 318:1737fs und

Howells EJ, Beltrán VH, Larsen NW, Bay LK, Willis BL, Van Oppen MJH. 2011. Coral thermal tolerance shaped by local adaptation of photosymbionts. Nature Climate Change DOI: 10.1038/NCLIMATE1330.

Howells EJ, Berkelmans R, van Oppen MJH, Willis BL, Bay LK. 2013. Historical thermal regimes define limits to coral acclimatization. Ecology 94:10781lis B

Hsu C-M, Keshavmurthy S, Denis V, Kuo C-Y, Wang J-T, Meng P-J, Chen C-A. 2012. Temporal and spatial variations in symbiont communities of catch bowl coral Isopora palifera (Scleractinis: Acroporidae) on reefs in Kenting National Park, Taiwan. Zoological Studies 51: 1343-1353.

Hughes TP, Baird AH, Bellwood DR, et al. 2003. Climate Change, Human Impacts, and the Resilience of Coral Reefs. Science 301:929 Chan

Hung T-C, Huang C-C, Shao K-T. 1998. Ecological survey of coastal water adjacent to nuclear power plants in Taiwan. Chemistry and Ecology. 15:129-142.

Hwang R-L, Tsai C-C, Lee T-M. 2004. Assessment of temperature and nutrient limitation on seasonal dynamics among species of Sargassum from a coral reef in southern Taiwan. Journal of Phycology 40:463 of $\mathrm{P}$

Iglesias-Prieto R, Beltran VH, LaJeunesse TC, Reyes-Bonilla H, Thome PE. 2004. Different algal symbionts explain the vertical distribution of dominant reef corals in the eastern Pacific. Proceeding of Royal Society of London B 271: 1757-1763.

Intergovernmental Panel on Climate Change. 2013. Climate Change 2013: The Physical Science Basis. Contribution of Working Group I to the Fourth Assessment Report of the Intergovernmental Panel of Climate Change, Cambridge University Press, Cambridge, UK.

Jan R-Q, Chen J-P, Lin C-Y, Shao K-T. 2001. Long-term monitoring of the coral reef fish communities around a nuclear power plant. Aquatic Ecology 35:233 Ecol

Jones R. 2008. Coral bleaching, bleaching-induced mortality, and the adaptive significance of the bleaching response. Marine Biology 154:65Biol

Jones AM, Berkelmans R, van Oppen MJH, Mieog JC, Sinclair W. 2008. A community change in the algal endosymbionts of a scleractinian coral following a natural bleaching event: field evidence of acclimatization. Proceeding of Royal Society of London B 275: 1359-1365

Keshavmurthy S, Hsu C-M, Kuo C-Y, Meng P-J, Wang J-T, Chen CA. 2012. Symbiont communities and host genetic structure of the brain coral Platygyra verweyi, at the outlet of a nuclear power plant and adjacent areas. Molecular Ecology 21:4393-4407.

Kozak KH, Wiens JJ. 2007. Climatic zonation drives latitudinal variation in speciation mechanisms. Proceedings of the Royal Society - Biological Sciences 274:2995gs of

Kramer, Degen, Buschbom, Hickler, Thuiller, Sykes. 2010. Modelling exploration of the future of European beech (Fagus sylvatica L.) under climate change - Range, abundance, genetic diversity and adaptive response. Forest Ecology and Management 259:10Ecol

Kuo C-Y, Yuen YS, Meng P-J, et al. 2012. Recurrent disturbances and the degradation of hard coral communities in Taiwan. PLoS ONE 7:e44364.

Ladner JT, Barshis DJ, Palumbi SR. 2011. Protein evolution in two co-occurring types of Symbiodinium: an exploration into the genetic basis of thermal tolerance in Symbiodinium 
666

667

668

669

670

671

672

673

674

675

676

677

678

679

680

681

682

683

684

685

686

687

688

689

690

691

692

693

694

695

696

697

698

699

700

701

702

703

704

705

706

707

708

709

710

711

clade D. BMC Evolutionary Biology 12:217lutio

LaJeunesse TC. 2001. Investigating the biodiversity, ecology, and phylogeny of endosymbiotic dinoflagellates in the genus Symbiodinium using the ITS region: in search of a S region: in evel marker. Journal of Phycology 37: 866of Ph

Lajeunesse TC. 2002. Diversity and community structure of symbiotic dinoflagellates from Caribbean coral reefs. Marine Biology 141:387iolog

LaJeunesse TC, Trench RK. 2000. Biogeography of two species of Symbiodinium (Freudenthal) inhabiting the intertidal sea anemone Anthopleura elegantissima (Brandt). Biological Bulletin 199:126-134

LaJeunesse TC, Bhagooli R, Hidaka M, DeVantier L, Done T, Schmidt GW, Fitt WK, HoeghGuldberg O. 2004. Closely related Symbiodinium spp. differ in relative dominance in coral reef host communities across environmental, latitudinal and biogeographic gradients. Marine Ecology Progress Series 284: 147-161.

LaJeunesse TC, Pettay DT, Sampayo EM, Phongsuwan N, Brown B, et al. 2010a. Long-standing environmental conditions, geographic isolation and host- symbiont specificity influence the relative ecological dominace and genetic diversification of coral endosymbionts in the genus Symbiodinium. Journal of Biogeography 37: 785-800.

Little AF, MJH van Oppen, BL Willis. 2004. Flexibility in algal endosymbioses shapes growth in reef corals. Science 304:1492-1494.

Loya Y, Sakai K, Yamazato K, Nakano Y, Sambali H, Van Woesik R. 2001. Coral bleaching: the winners and the losers. Ecology Letters 4:122y Let

Marshall J, McCulloch M. 2002. An assessment of the $\mathrm{Sr} / \mathrm{Ca}$ ratio in shallow water hermatypic corals as a proxy for sea surface temperature. Geochimica et Cosmochimica Acta 66:3263mica A

Marshall P, Baird A. 2000. Bleaching of corals on the Great Barrier Reef: differential susceptibilities among taxa. Coral Reefs 19:155-163.

Meng P-J, Lee H-J, Wang J-T, Chen C-C, Lin H-J, Tew KS, Hsieh W-J. 2008. A long-term survey on anthropogenic impacts to the water quality of coral reefs, southern Taiwan. Environmental Pollution 156:67ment

Meesters EH, Nieuwland G, Duineveld G, Kok A, Bak R. 2002. RNA/DNA ratios of scleractinian corals suggest acclimatisation/adaptation in relation to light gradients and turbidity regimes. Marine Ecology Progress Series, 227 233ology Monaco CJ, Helmuth B. 2011. Tipping points, thresholds and the keystone role of physiology in marine climate change research. Advances in Marine Biology 60:123s in

Nussey DH, Postma E, Gienapp P, Visser ME. 2005. Selection on heritable phenotypic plasticity in a wild bird population. Science 310:304.

Oliver TA, Palumbi SR. 2011. Do fluctuating temperature environments elevate coral thermal tolerance? Coral Reefs 30:429eefsD

Ortiz JC, González-Rivero M, Mumby PJ. 2012. Can a thermally tolerant symbiont improve the future of Caribbean coral reefs? Global Change Biology 19:273Chang

Parmesan C, Yohe, G. 2003. A globally coherent fingerprint of climate change impacts across natural systems. Nature 421:37-42.

Pier J-J. 2011. Power uprate effect on thermal effluent of nuclear power plants in Taiwan. In: Nuclear Power-Operation, Safety and Environment (ed Tsvetkov P). InTech publication, Rijeka, Croatia. 287licatPochon X, Gates RD. 2010. A new Symbiodinium clade (Dinophyceae) from soritid foraminifera in Hawai'i. Molecular Phylogenetics and 
712

713

714

715

716

717

718

719

720

721

722

723

724

725

726

727

728

729

730

731

732

733

734

735

736

737

738

739

740

741

742

743

744

745

746

747

748

749

750

751

752

753

754

Evolution 56:492oluti

Richter SS, Kipfer TT, Wohlgemuth TT, Guerrero CCC, Ghazoul JJ, Moser BB. 2012. Phenotypic plasticity facilitates resistance to climate change in a highly variable environment. Oecologia 169:269aenot

Richier S, Furla P, Plantivaux A, Merle P-L, Allemand D. 2005. Symbiosis-induced adaptation to oxidative stress. The Journal of Experimental Biology 208:277nal o

Riegl B, Purkis S, Al-Cibahy A, Abdel-Moati M. 2011. Present Limits to Heat-Adaptability in Corals and Population-Level Responses to Climate Extremes. PLoS ONE 6:e24802.

Rowan RR, Knowlton NN, Baker AA, Jara JJ. 1997. Landscape ecology of algal symbionts creates variation in episodes of coral bleaching. Nature 388:265 vari

Rowan R. 2004. Coral bleaching: thermal adaptation in reef coral symbionts. Nature 430:742s. ch

Rowan R, Powers DA. 1991. Molecular genetic identification of symbiotic dinoflagellates (zooxanthellae). Marine Ecology Progress Series 71:65-73.

Shaish L, Abelson A, Rinkevich B. 2007. How plastic can phenotypic plasticity be? The branching coral Stylophora pistillata as a model system. PLoS ONE 2:e644.

Sampayo EM, Ridgeway T, Bongaerts P, Hoegh-Guldberg O. 2008. Bleaching susceptibility and mortality of corals are determined by fine-scale differences in symbiont type. Proceedings of the National Academy of Sciences 105: 10444 of the

Stat M, Gates RD. 2011. Clade D Symbiodinium in Scleractinian Corals: A an Corals: A : A e D emy of Sciencesy of corals are determined by fine-scale diJournal of Marine Biology lurn

Strychar KB, Sammarco PW. 2009. Exaptation in corals to high seawater temperatures: Low concentrations of apoptotic and necrotic cells in host coral tissue under bleaching conditions. Journal of Experimental Marine Biology And Ecology 369:31 of

Thornhill DJ, LaJeunesse TC, Kemp DW, Fitt WK, Schmidt GW. 2006. Multi-year, seasonal genotypic surveys of coral-algal symbioses reveal prevalent stability or post-bleaching reversion. Marine Biology 148: 711ology

Tonk L, Sampayo EM, Weeks S, Magno-Canto M, Hoegh-Guldberg O. 2013. Host-Specific Interactions with Environmental Factors Shape the Distribution of Symbiodinium across the Great Barrier Reef. PLoS ONE 8(7): e68533.

Traill LW, Lim MLM, Sodhi NS, Bradshaw CJA. 2010. Mechanisms driving change: altered species interactions and ecosystem function through global warming. Journal of Animal Ecology 79:937 of A

van Oppen MJH, Souter P, Howells EJ, Heyward A, Berkelmans R. 2011. Novel genetic diversity through somatic mutations: fuel for adaptation of reef corals? Diversity 3:405ity N

Vose RS, Easterling DR, Gleason B. 2005. Maximum and minimum temperature trends for the globe: An update through 2004. Geophysical Research Letters 32:L23822.

Warner ME, LaJeunesse TC, Robison JD, Thur RM. 2006. The ecological distribution and comparative photobiology of symbiotic dinoflagellates from reef corals in Belize: Potential implications for coral bleaching. Limnology and Oceanography 51: 1887-1897

Weber M, Medina M. 2012. The role of microalgal symbionts (Symbiodinium) in holobiont physiology. Advances in Botanical Research 64:119s in 


\section{Table 1 (on next page)}

Comparison of coral assemblages between 1986 and 2010 at NPP OL location. 


\section{Table 1.}

\begin{tabular}{|c|c|c|c|c|c|}
\hline Year & $\begin{array}{l}\text { Major assemblages } \\
\text { at NPP OL }(3 \mathrm{~m})\end{array}$ & $\%$ of total cover & $\begin{array}{l}\text { Minor assemblages at NPP } \\
\text { OL }(3 \mathrm{~m})\end{array}$ & $\%$ of total cover & Reference \\
\hline \multirow[t]{7}{*}{1986} & Acropora & 24.20 & Montastrea & 3.35 & Dai, 1988 \\
\hline & Montipora & 33.69 & Pocillopora & 2.27 & \\
\hline & & & Isopora & 2.52 & \\
\hline & & & Porites & 1.84 & \\
\hline & & & Seriatopora & 1.58 & \\
\hline & & & Stylophora & 0.24 & \\
\hline & & & Pavona & 0.14 & \\
\hline \multirow[t]{6}{*}{2010} & Galaxea & 21.20 & Favites & 5.40 & This study \\
\hline & Montipora & 21.70 & Porites & 3.00 & \\
\hline & & & Pavona & 3.30 & \\
\hline & & & Acropora & 0.70 & \\
\hline & & & Seriatopora & Not detected & \\
\hline & & & Stylophora & Not detected & \\
\hline
\end{tabular}




\section{Table 2 (on next page)}

Marginal tests with host genus HPCO1 and 2 and Symbiodinium 
Table 2a. Marginal tests with host genus HPCO1 and 2 and Symbiodinium type

\begin{tabular}{lrrrr} 
Variable & Pseudo-F & P & \multicolumn{2}{c}{ \% variance } \\
explained r & \\
PAR(Kd) & 0.83722 & 0.485 & & 53.47 \\
Tw & 0.62396 & 0.681 & 27.24 \\
Ts & 1.5853 & 0.204 & 11.53 \\
Tavg & 1.252 & 0.315 & 8.28 \\
Tsd & 1.3608 & 0.305 & 4.61 \\
HPCO1ge & 0.35728 & 0.801 & -1.13 \\
n & & & \\
HPCO2ge & 4.369 & 0.006 & -4.01 \\
n & & &
\end{tabular}

Table 2b. Marginal tests with host species HPCO1 and 2 Symbiodinium type

\begin{tabular}{|c|c|c|c|}
\hline Variable & Pseudo-F & $\mathrm{P}$ & $\begin{array}{l}\% \text { variance } \\
\text { explained }\end{array}$ \\
\hline $\operatorname{PAR}(\mathrm{Kd})$ & 0.83722 & 0.483 & 53.87 \\
\hline $\mathrm{Tw}$ & 0.62396 & 0.637 & 29.55 \\
\hline Ts & 1.5853 & 0.2 & 11.3 \\
\hline Tavg & 1.252 & 0.314 & 5.26 \\
\hline Tsd & 1.3608 & 0.27 & 3.72 \\
\hline HPCO1sp & 1.6455 & 0.209 & -3.7 \\
\hline $\mathrm{HPCO} 2 \mathrm{sp}$ & 5.5322 & 0.001 & \\
\hline
\end{tabular}

Table 2c. Marginal tests with host genus HPCO1 and 2 and Symbiodinium clade

\begin{tabular}{|c|c|c|c|}
\hline Variable & Pseudo-F & $\mathrm{P}$ & $\begin{array}{l}\% \text { variance } \\
\text { explained }\end{array}$ \\
\hline $\operatorname{PAR}(\mathrm{Kd})$ & 0.79276 & 0.482 & 96.98 \\
\hline $\mathrm{Tw}$ & 1.7847 & 0.182 & 3.82 \\
\hline Ts & 3.766 & 0.071 & 0.58 \\
\hline Tavg & 4.862 & 0.063 & 0.1 \\
\hline Tsd & 11.06 & 0.029 & 0 \\
\hline $\begin{array}{l}\text { HPCO1ge } \\
\mathrm{n}\end{array}$ & 1.4382 & 0.203 & -0.09 \\
\hline $\begin{array}{l}\mathrm{HPCO} 2 \mathrm{ge} \\
\mathrm{n}\end{array}$ & 1.8179 & 0.165 & -1.39 \\
\hline
\end{tabular}

Table 2c. Marginal tests with host genus HPCO1 and 2 and Symbiodinium clade

\begin{tabular}{lrrrr} 
Variable & Pseudo-F & P & \multicolumn{3}{c}{$\begin{array}{l}\text { \% variance } \\
\text { explained }\end{array}$} \\
PAR(Kd) & 0.79276 & 0.473 & & 96.86 \\
Tw & 1.7847 & 0.197 & 3.88 \\
Ts & 3.766 & 0.055 & 0.59 \\
Tavg & 4.862 & 0.066 & 0.14 \\
Tsd & 11.06 & 0.031 & 0 \\
HPCO1sp & 0.3212 & 0.659 & -0.08
\end{tabular}


$\begin{array}{llll}\text { HPCO2sp } & 4.9074 & 0.057 & -1.4\end{array}$ 


\section{Figure 1}

Map of the study area and sampling locations in Kenting, southern Taiwan.

Eight sampling sites including the nuclear power plant outlet (NPP OL) sites are shown by black stars.
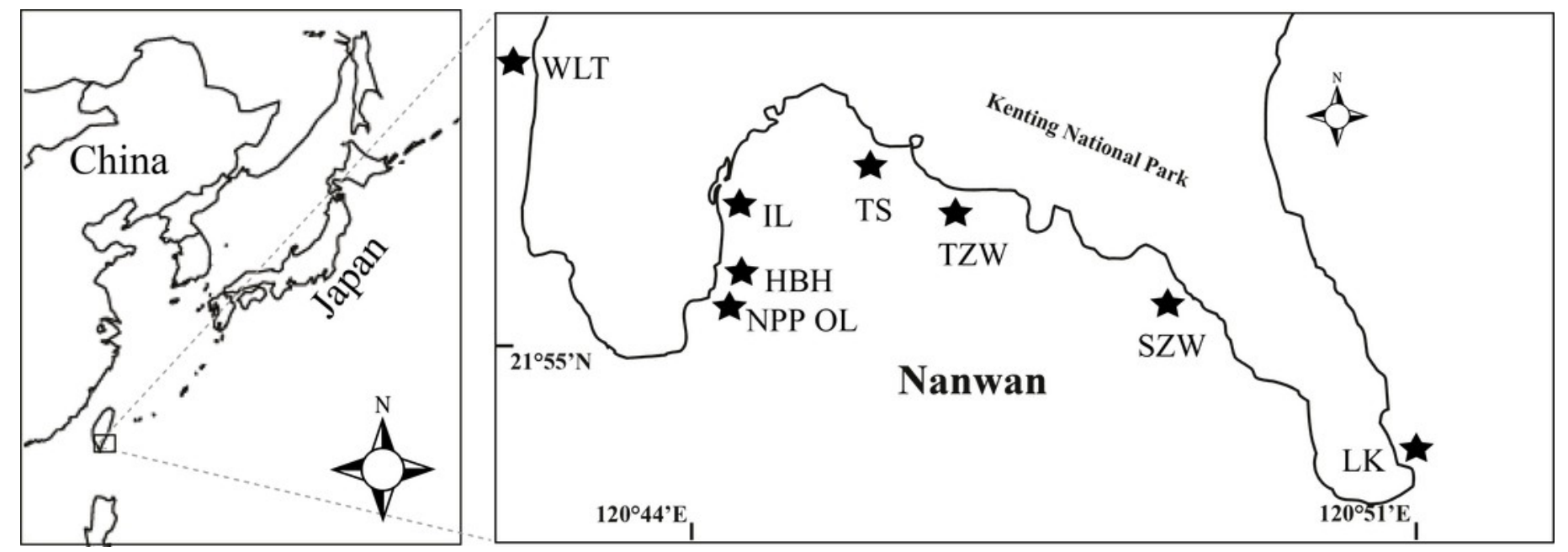


\section{Figure 2}

Mean seawater temperatures

NPP OL (red line) and control (grey lines) locations measured at $3 \mathrm{~m}$ depth from 1986 to 1992 (A). Monthly average seawater temperatures at six locations including NPP OL (B). 


\section{Figure 3}

Contour diagram for the seawater temperature at Nanwan.

The contour diagram of the sea surface temperature in Nanwan from May 2009 - May 2010. The red plume at the left is the constant hot water output form the nuclear power plant. The seawater near the nuclear power plant outlet are constantly hot irrespective of season. 

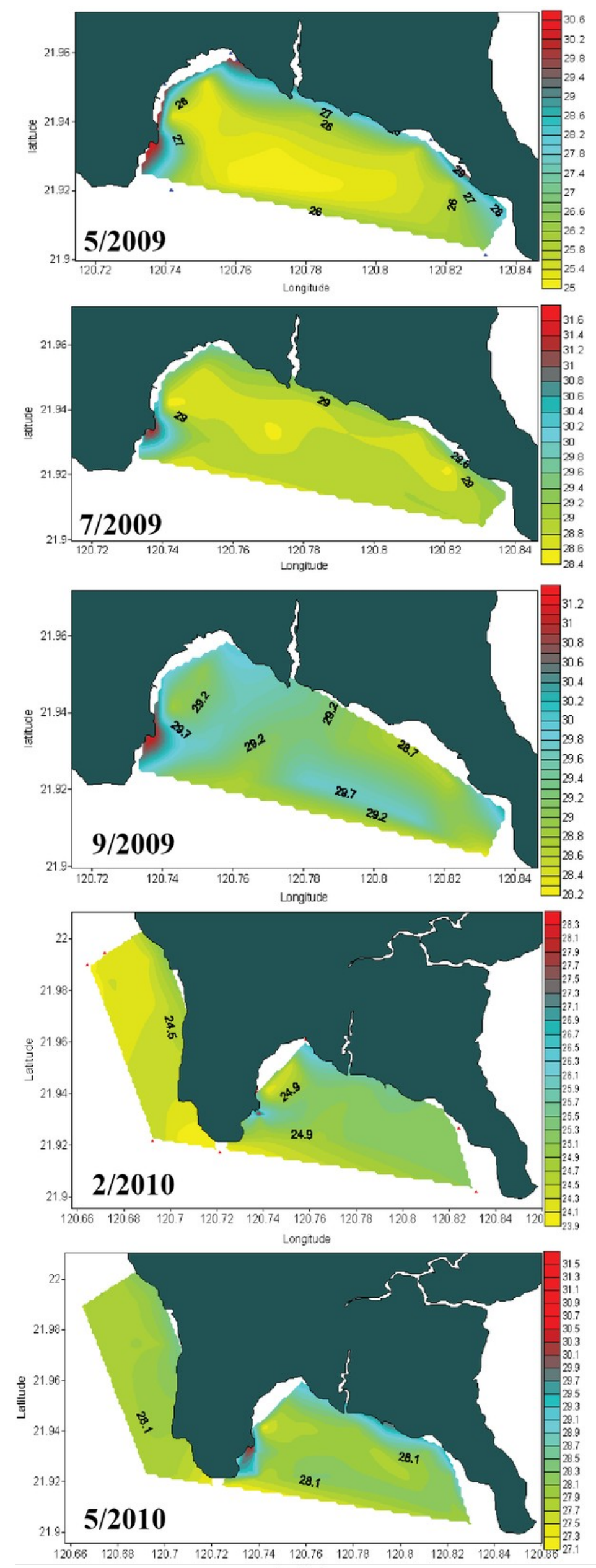

PeerJ reviewing PDF | (v2013:08:756:1:1:NEW 11 Mar 2014) 


\section{Figure 4}

Symbiodinium composition in 16 coral genera sampled at $3 \mathrm{~m}$ and $7 \mathrm{~m}$ seven locations and shown separately for NPP OL.

Distribution of Symbiodinium clades based on the restriction length fragment polymorphism (RFLP) at $3 \mathrm{~m}$ and $7 \mathrm{~m}$ in all coral hosts at 8 sites (A). Distribution of Symbiodinium clades in individual genera sampled from 8 sites (B) and distribution of Symbiodinium clades in 16 genera in NPP OL 3m and 7m (C). Brown bars = Symbiodinium clade C; light brown bars = Symbiodnium clades $\mathrm{C}+\mathrm{D}$, and yellow bars $=$ Symbiodinium clade D.

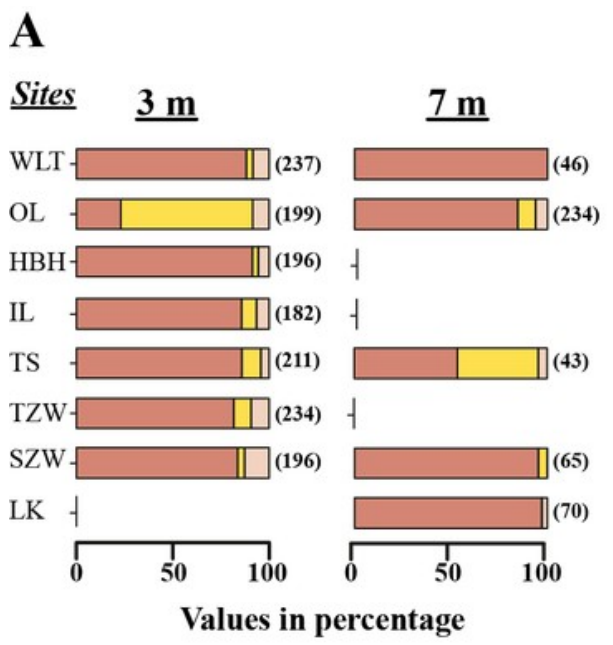

C

B

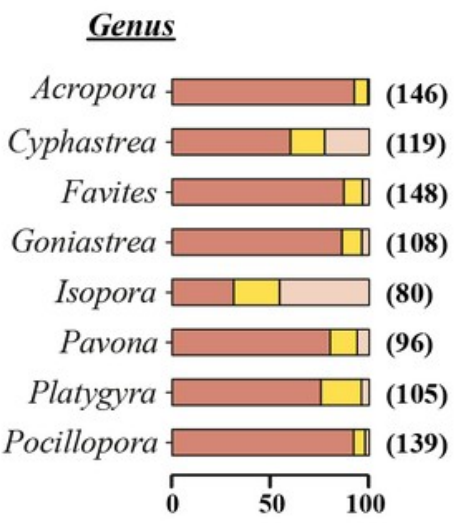

Values in percentage $\underline{\text { Genus }}$

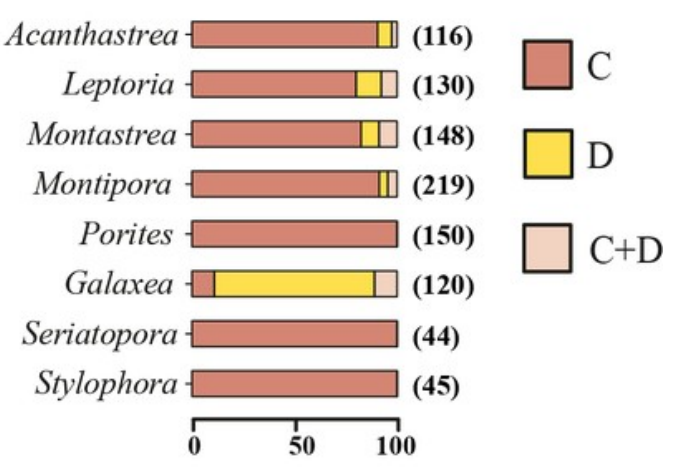

Values in percentage

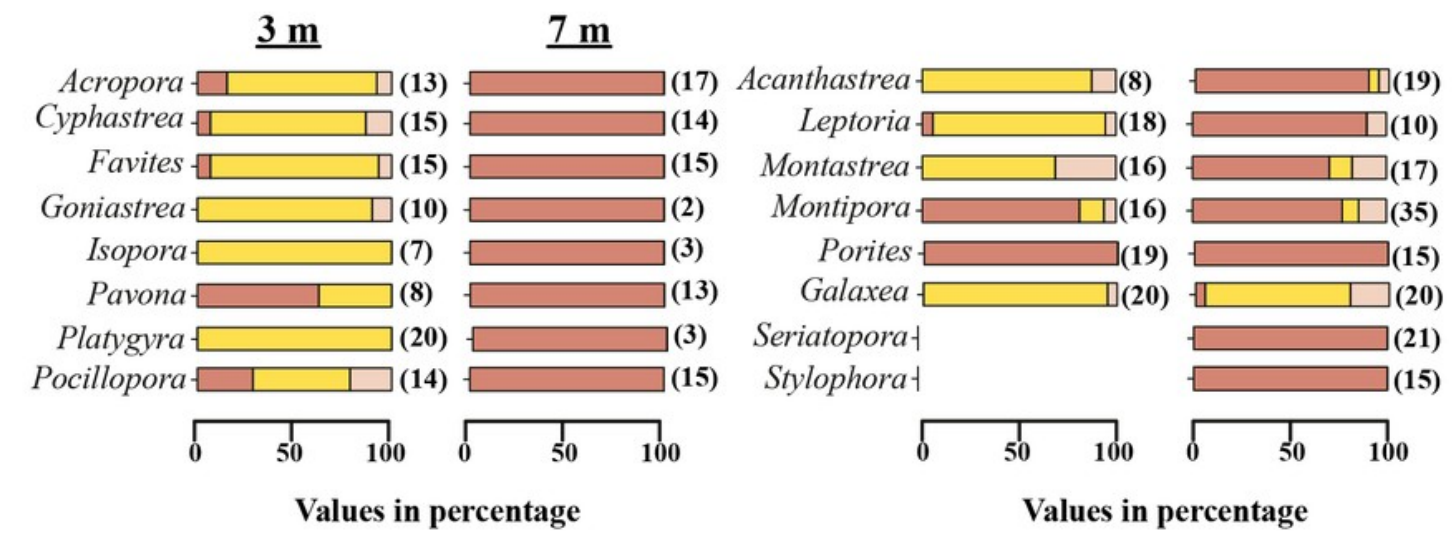




\section{Figure 5}

One-way diamond mean plots of Symbiodinium clade C and Symbiodinium clade In 16 coral genera at 8 locations in Kenting ( $3 \mathrm{~m}$ and $7 \mathrm{~m}$ ) (A). Comparison of total Symbiodinium clade $\mathrm{C}$ and Symbiodinium clade D composition at NPP OL (3 $\mathrm{m}$ and $7 \mathrm{~m}$ ).

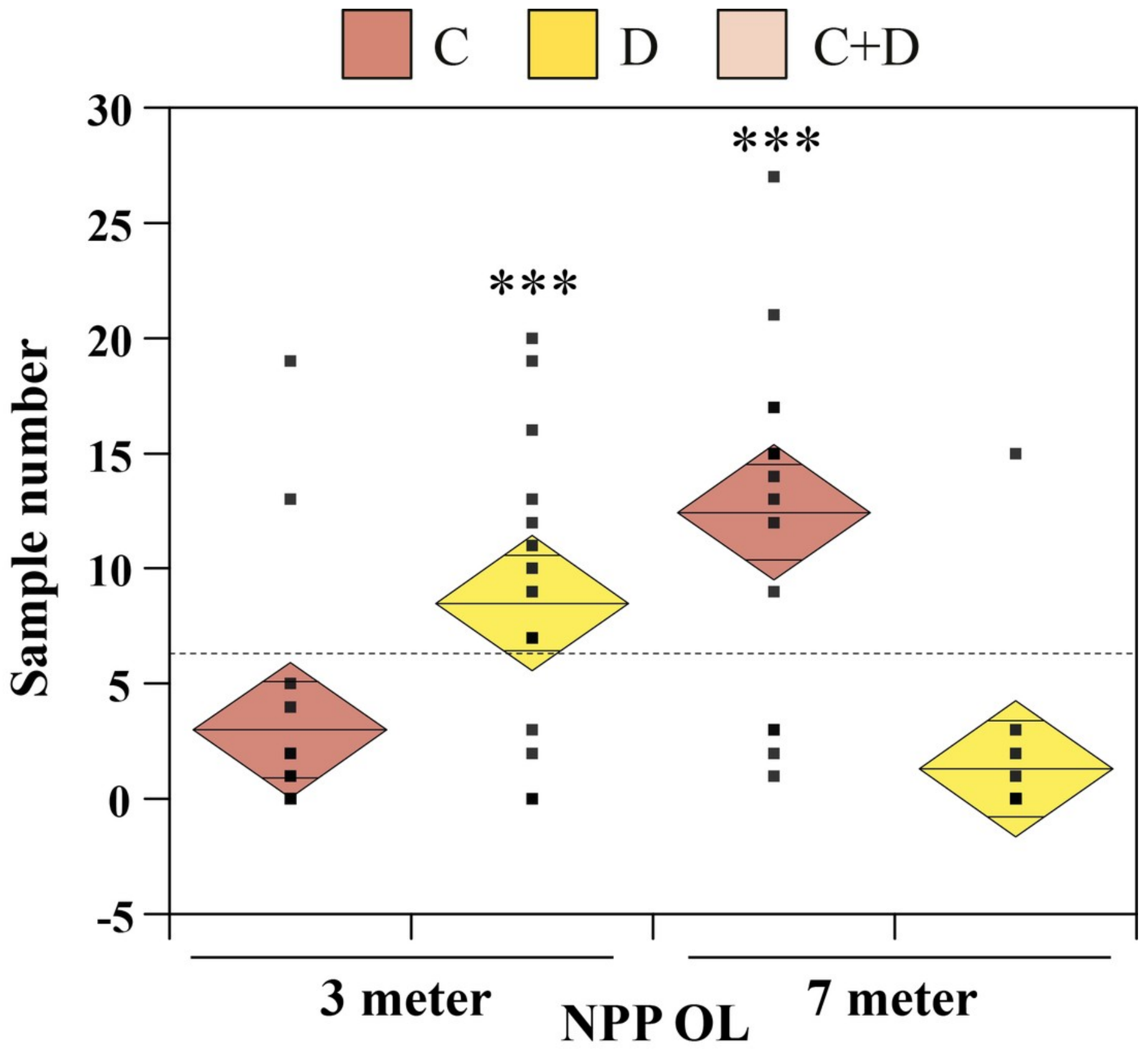




\section{Figure 6}

Coral communities at NPP OL over time showing the condition of reefs at $3 \mathrm{~m}$ and $7 \mathrm{~m}$ in 1986, 1995 and 2010
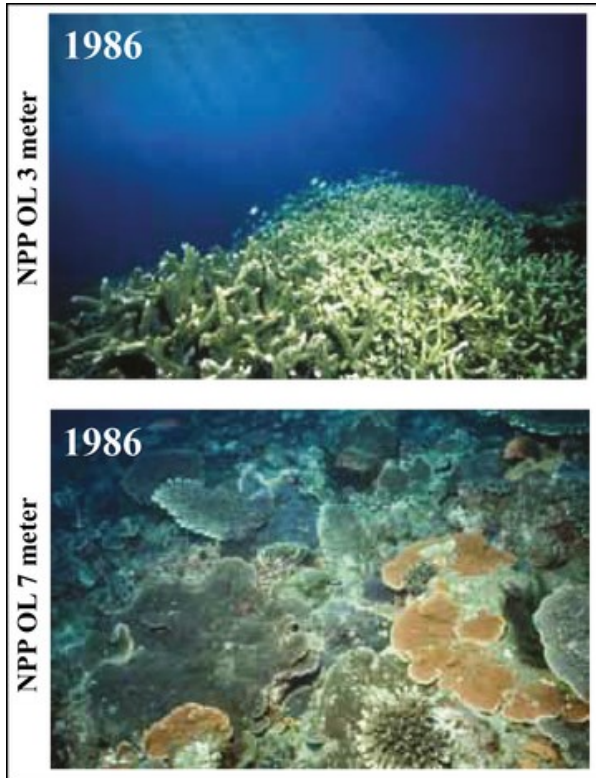

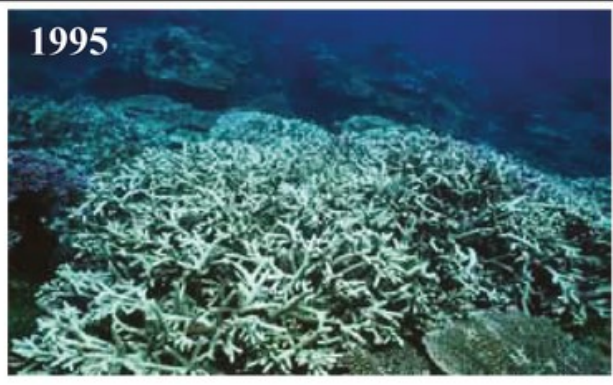

\section{5}

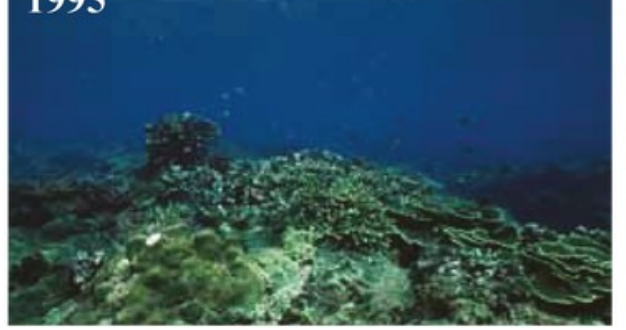

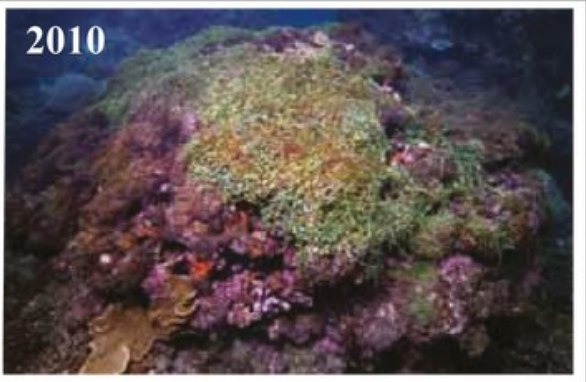

2010

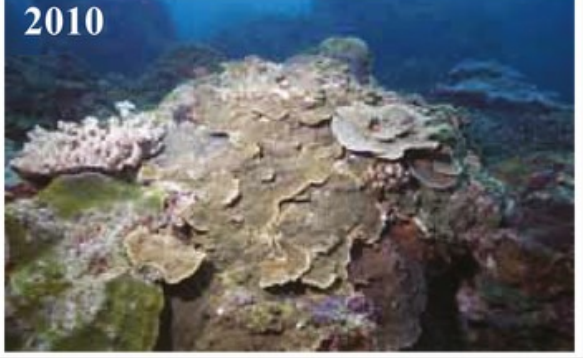




\section{Figure 7}

Coral host composition at $3 \mathrm{~m}$ and $7 \mathrm{~m}$ NPP OL site

Relative abundance of coral genera in 1986, 1995 and 2010 at NPP OL $3 \mathrm{~m}$ and $7 \mathrm{~m}$. Black dotted line shows the change in Acropora abundance over time. Yellow dotted line shows the relative abundance of Montipora over time.
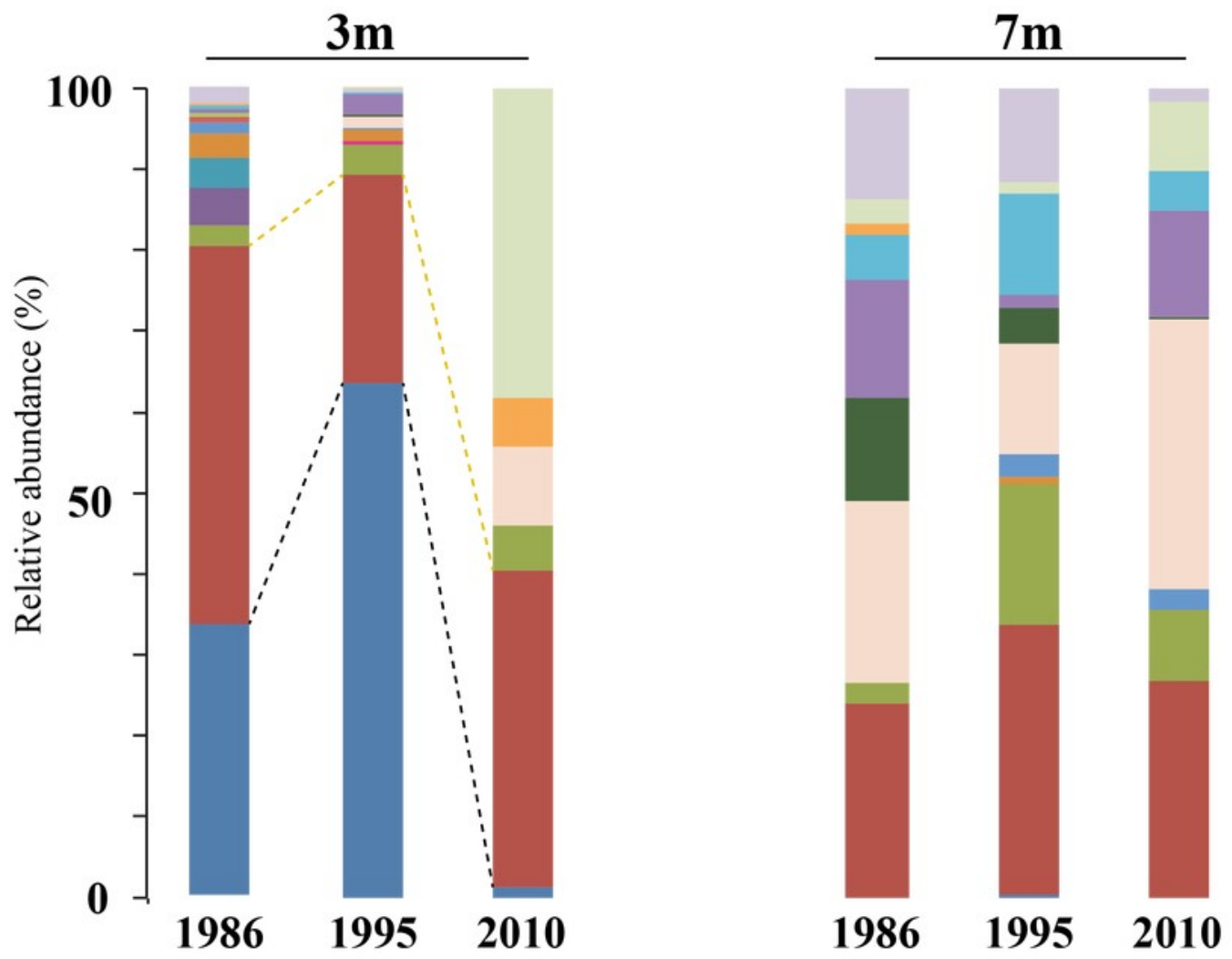

Acropora

Montipora

Porites

Goniastrea

Favites

Platygyra

Pavona

Galaxea

Stylophora

Seriatopora

Leptoria

Acanthastrea

Cyphastrea

Pocillopora

Isopora

Montastrea 


\section{Figure 8}

Distance based RDA plots

Environmental parameters and host genus information to Symbiodinium clades using the all the host genera $(A)$. Environmental parameters and host genus information to Symbiodinium types using the all the host genera $(B)$ and relation between genera and sampling sites $(C)$. Biplot projections are shown for the effect of environmental factors including host data (HPCO1 and 2) and for the occurrence of a particular genera in relation to a sampling site. 'the \% of fitted' explains the percentage of the variability in the original data explained by the axis, and 'the $\%$ of total variation' indicates the percentage of variation in the fitted matrix explained by the axis. Abbreviated site names are; Wanlitung (WLT), NPP OL, Houbihu (HBH), NPP Inlet (IL), Taioshih (TS), Tanziwan (TZW), Sanjiawan (SJW), and Longken (LK), and NPP Outlet ( NPP OL) 
A
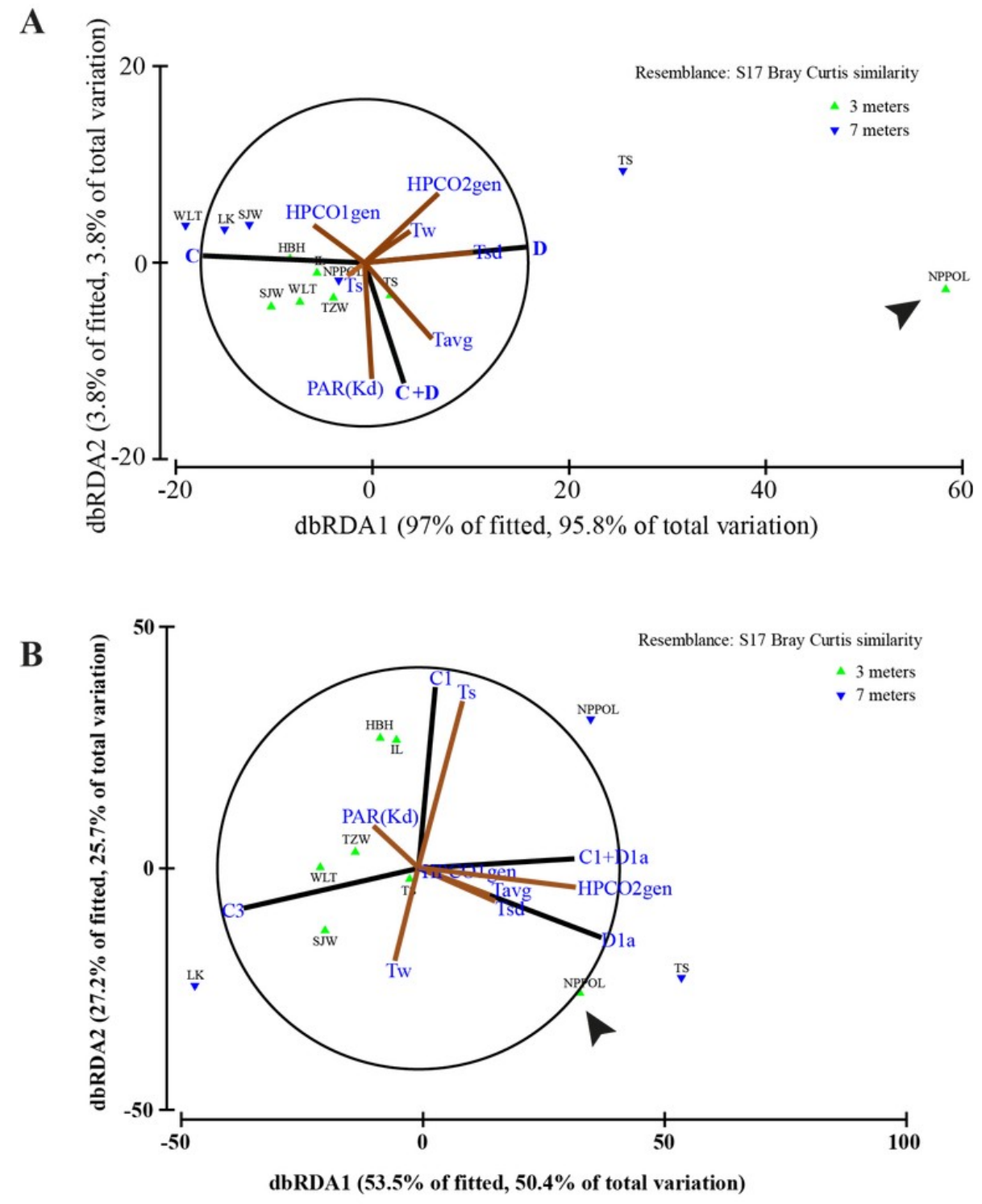

C

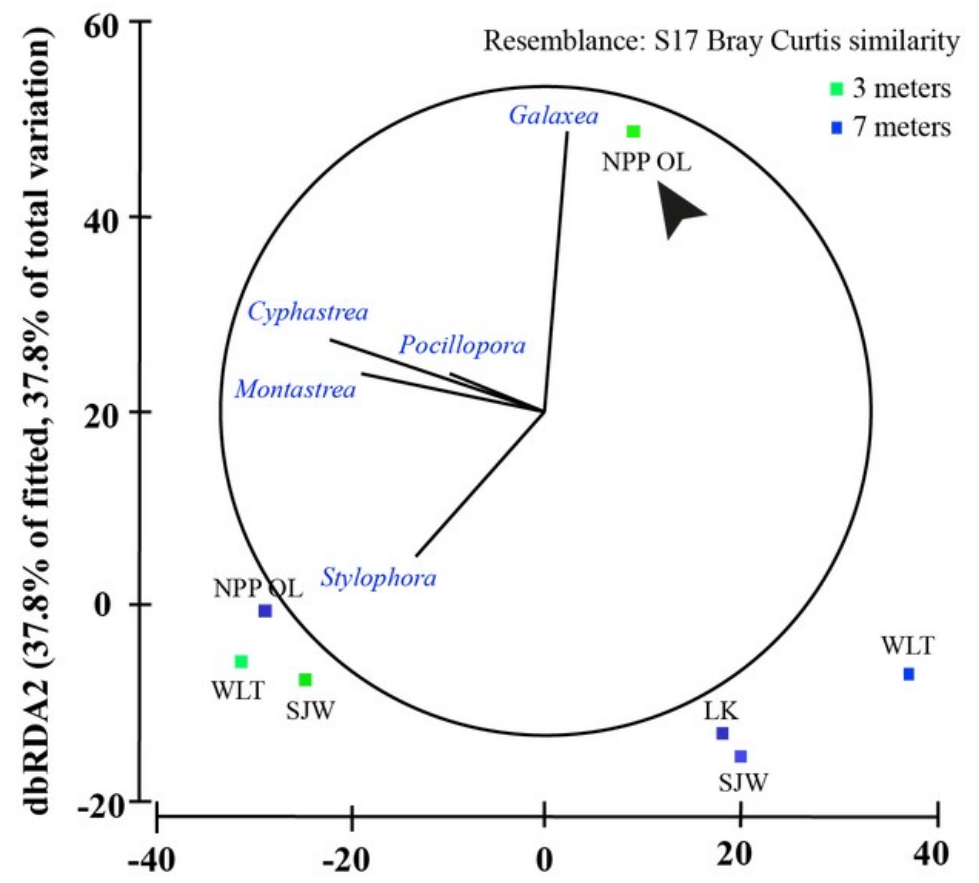

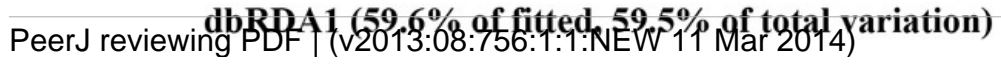

